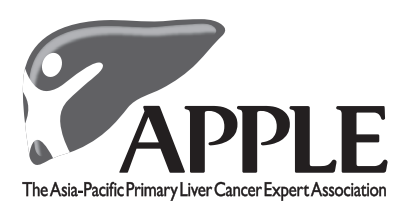

President

Ann-Lii Cheng (Taipei)

Secretary General

Jinsil Seong (Seoul)

Scientific Committee Chair

Joong-Won Park (Goyang)

Namiki Izumi (Tokyo)

Publication

Michiie Sakamoto (Tokyo)

Treasurer

Chih-Hung Hsu (Taipei)

Past President

Masatoshi Kudo (Osaka)

Hosting Chairman APPLE 2018 Jinsil Seong (Seoul)

\section{Past Chairmen}

Sheng-Long Ye (Shanghai)

Ronnie Poon (Hong Kong)

Pierce Chow (Singapore)

\section{Council Members}

Hiroaki Nagano (Yamaguchi)

Masafumi Ikeda (Kashiwa)

Takamichi Murakami (Osaka)

Guohong Han (Xi'an)

Junqi Niu (Jilin)

Feng Shen (Shanghai)

Iren $\mathrm{Ng}$ (Hong Kong)

Kyung-Suk Suh (Seoul)

Soon Ho Um (Seoul)

Seung Kew Yoon (Seoul)

Chiun Hsu (Taipei)

Toh Han Chong (Singapore)

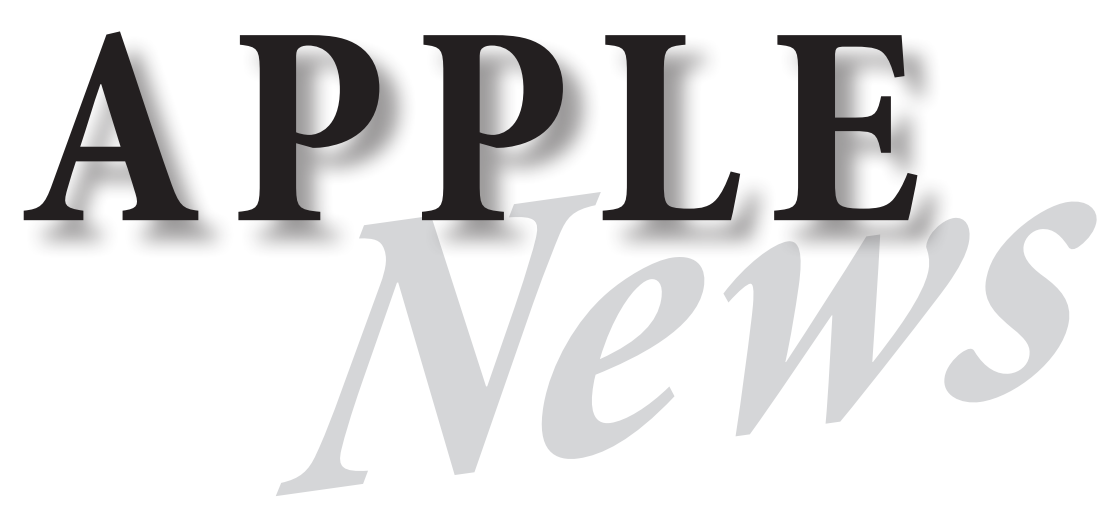

\section{Aims}

Primary liver cancer is an extremely malignant disease, and $80 \%$ of patients are found in Asian countries. The APPLE Meetings have been initiated to provide a platform for regional and international experts to exchange information on the latest advancements in primary liver cancer treatment. The meetings are aimed at bridging gaps in the basic science and clinical aspects of liver cancer among specialists, with the ultimate aim of disseminating the results of laboratory research and clinical trials in liver cancer among professionals.

\section{History}

The APPLE Meetings take place annually and have been hosted on rotation by the Korean Liver Cancer Study Group, the Liver Cancer Study Group of Japan, and the Chinese Liver Cancer Study Group. The 1st meeting of the group took place in Incheon in 2010, the 2nd in Osaka in 2011, the 3rd in Shanghai in 2012, and the 4th in Busan in 2013. In 2014, APPLE changed its policy and decided to expand its congress venues from three countries to include all Asian countries, and the 5th APPLE Meeting was held in Taipei in 2014. The 6th APPLE Meeting was held in Osaka in 2015, the 7th in Hong Kong in 2016, and the 8th in Singapore in 2017.

\section{Next Meeting}

The 9th APPLE Meeting

Seoul, July 6-8, 2018

www.applecongress.org 